OPEN ACCESS

Edited by:

Xiuchen Wu,

Beijing Normal University, China

Reviewed by:

Mariangela N. Fotelli,

Forest Research Institute, Hellenic

Agricultural Organization, Greece

Shan Li,

Shaanxi University of Science and Technology, China

*Correspondence: Bingcheng $X_{U}$

Bcxu@ms.iswc.ac.cn

Specialty section:

This article was submitted to

Functional Plant Ecology,

a section of the journal

Frontiers in Plant Science

Received: 11 June 2021 Accepted: 27 September 2021

Published: 22 October 2021

Citation:

Xu W, Deng X, Xu B, Palta J and Chen Y (2021) Soil Water Availability

Changes in Amount and Timing Favor

the Growth and Competitiveness of Grass Than a Co-dominant

Legume in Their Mixtures.

Front. Plant Sci. 12:723839.

doi: 10.3389/fp/s.2021.723839

\section{Soil Water Availability Changes in Amount and Timing Favor the Growth and Competitiveness of Grass Than a Co-dominant Legume in Their Mixtures}

\author{
Weizhou $X_{u^{1,2}}$, Xiping Deng ${ }^{2,3}$, Bingcheng $X_{u^{2,3 *}}$, Jairo A. Palta ${ }^{4,5}$ and Yinglong Chen ${ }^{4}$ \\ ${ }^{1}$ College of Life Sciences, Yulin University, Yulin, China, ${ }^{2}$ State Key Laboratory of Soil Erosion and Dryland Farming on \\ the Loess Plateau, Northwest A\&F University, Yangling, China, ${ }^{3}$ Institute of Soil and Water Conservation, Chinese Academy \\ of Sciences and Ministry of Water Resources, Yangling, China, ${ }^{4}$ School of Agriculture and Environment, The UWA Institute \\ of Agriculture, The University of Western Australia, Perth, WA, Australia, ${ }^{5}$ CSIRO Agriculture and Food, Wembley, WA, \\ Australia
}

The grasslands on the semi-arid Loess Plateau of China are expected to be particularly responsive to the size and frequency changes of extreme precipitation events because their ecological processes are largely driven by distinct soil moisture pulses. However, the plant growth and competitiveness of co-dominant species in response to the changes in the amount and timing of soil water are still unclear. Thus, two codominant species, Bothriochloa ischaemum and Lespedeza davurica, were grown in seven mixture ratios under three watering regimes $[80 \pm 5 \%$ pot soil capacity (FC) (high watering), $60 \pm 5 \%$ FC (moderate watering), and $40 \pm 5 \%$ FC (low watering)] in a pot experiment. The soil water contents were rapidly improved from low to moderate water and from moderate to high water, respectively, at the heading, flowering, and maturity stages of $B$. ischaemum, and were maintained until the end of the growing season of each species. The biomass production of both species increased significantly with the increased soil water contents, particularly at the heading and flowering periods, with a more pronounced increase in $B$. ischaemum in the mixtures. The root/shoot ratio of both species was decreased when the soil water availability increased at the heading or flowering periods. The total biomass production, water use efficiency (WUE), and relative yield total $(R Y T)$ increased gradually with the increase of $B$. ischaemum in the mixtures. The relative competition intensity was below zero in $B$. ischaemum, and above zero in $L$. davurica. The competitive balance index calculated for $B$. ischaemum was increased with the increase of the soil water contents. Bothriochloa ischaemum responded more positively to the periodical increase in soil water availability than $L$. davurica, indicating that the abundance of $B$. ischaemum could increase in relatively wet seasons or plentyrainfall periods. In addition, the mixture ratio of 10:2 (B. ischaemum to $L$. davurica) was the most compatible combination for the improved biomass production, WUE, and RYTs across all soil water treatments.

Keywords: growth period, soil water availability, biomass production, competition, mixture ratio 


\section{INTRODUCTION}

Rainfall variability greatly affects the structure and function of ecosystems globally, especially in the arid and semi-arid regions (Knapp et al., 2003; Post and Knapp, 2020). The response of the plant community to rainfall fluctuations is an integrative outcome from each species, particularly the dominant species. Thus examining their responses to altered rainfall patterns can provide a better understanding and prediction of community changes (Schwinning et al., 2004; Báez et al., 2013). The eco-physiological response of dominant species to the changes in rainfall pattern in the arid and semi-arid areas, not only depends on the capability of drought resistance in individual species, but also on the ability to grow and recover after rainfalls, largely influenced by the antecedent soil water availability (Niu et al., 2016; Xiong et al., 2017). Plant biomass allocation, water use strategies, and plant-plant interactions (either facilitation or competition) are the key integrative measures of the ecosystem function, which have been the major focus in plant eco-physiology research over the last decade (Soliveres et al., 2012; Xu et al., 2013; Foxx and Florian, 2019). In the Inner Mongolian region of north China, the stability of primary productivity in grassland communities is high, mainly because there is a strong compensatory effect among the performance of species under fluctuant rainfall conditions (Bai et al., 2004). It is likely that the intensity and outcome of plant-plant interactions may change with the soil water availability. Therefore, intraspecific competition may replace interspecific facilitation as water stress is alleviated (GarcíaCervigón et al., 2013; Adler et al., 2018). Such shift in the competitive intensities and compensatory effect among species might be the key coexistence mechanism for stabilizing the grassland community productivity when encountering drought stress (Grant et al., 2014).

Grasslands play important roles in both the economy and ecology of the semi-arid region on the Loess Plateau of China, which is one of the most sensitive ecosystems to adapt to the changes in rainfall pattern during the growing season in water-limited regions (Fu et al., 2010; Lee et al., 2014; Bhandari et al., 2015). The construction of artificial grasslands with high regional adaptation was an effective practice to address the problems created by grassland degradation, and it is the key measure to ensure the sustainable development of grasslands in the region (Shan and Xu, 2009; Xu et al., 2011a). In addition, the use of grass and legume mixtures has been widely proposed in this region because legumes fix nitrogen $(\mathrm{N})$ into the rhizosphere, and can ameliorate the microsite in terms of nutrient availability (Xu et al., 2011b). Thus, the introduction of legumes at suitable mixture ratios into gramineous plants for establishing artificial grasslands is beneficial for improving biomass production, water use, and ecosystem stability, because there are complementary and mutually reinforcing roles between them (Xu et al., 2011b, 2013). Although the role of the strategies of biomass allocation and the specific responses of species in grassland communities to soil water availability have been highlighted in previous studies (Padilla et al., 2009; Niu et al., 2011;
Soliveres et al., 2013; Xiong et al., 2017), detailed information on these strategies and specific responses of grasslands with mixed grass and legume to the amount and timing of soil water changes is scarce. With the advent of climate change, rainfall has become the most important driver of biological activity in the arid and semi-arid regions, and the assessment of the specific responses of co-occurring species to rainfall pulses would favor the prediction of changes in ecological processes and the vulnerability of grassland ecosystems (Fay, 2009).

However, construction of artificial grasslands in this region is currently limited by the lack of appropriate grass species and its single grassland structure, with low eco-adaptation to local environments (Shan and Xu, 2009). Moreover, the response of the grassland ecosystem to the altered rainfall patterns is largely driven by the dominant native plant species in the communities (Schwinning et al., 2004; Xiong et al., 2017). Bothriochloa ischaemum (L.) Keng and Lespedeza davurica (Laxm.) Schindl are two co-occurring native species widely distributed across semi-arid grassland communities. Bothriochloa ischaemum is a perennial herbaceous grass, while L. davurica is a perennial leguminous subshrub. The two species have great eco-adaptation to the regional environment and climate and play important roles in reducing soil and water loss and maintaining distinctive natural landscapes in the area. Understanding how these co-occurring native species respond to altered water availability in mixtures will provide information on their coexistence mechanisms and will aid in the selection of appropriate measures in establishing artificial grasslands. Our previous studies evaluated the biomass, competitive ability, and water use efficiency (WUE) of B. ischaemum and L. davurica under three constant water regimes and four fertility treatments (Xu et al., 2011a,b, 2013). The results showed that there exist complementary effects between both species when growing together, with the biomass relative yield total (RYT) values of their mixtures being generally greater than 1. We also investigated the root morphological traits of $B$. ischaemum when mixed with $L$. davurica under soil watering treatments, which showed that the soil moisture availability at the early growing season strongly increased its root growth (Wang et al., 2018).

The focus of the current study was on the response of co-occurring species to the changes in soil water availability because the changes in rainfall patterns with the advent of climate change are expected to cause more frequent extreme rainfalls and longer intervals between events (Liu et al., 2012; Niu et al., 2016). Knowledge about the biomass allocation strategy and relative competitive ability of both species in response to varying mixture ratios and watering regimes is still unknown. Therefore, the aims of the present study were: (1) to evaluate the responses of the biomass allocation and water use of both species to the changes in the amount and timing of soil watering availability, (2) to identify the plant-plant interactions in response to varying mixture ratios and watering regimes, and (3) to determine which mixture ratio of the two species is the most suitable for artificial grasslands based on their interacting coexistence mechanisms. 


\section{MATERIALS AND METHODS}

\section{Plant Materials and Growth Conditions}

The seeds of both species were collected in the autumn of 2011 from an experimental field at the Ansai Research Station (ARS) of the Chinese Academy of Sciences (CAS), located at the semiarid hilly-gully region on the Loess Plateau $\left(36^{\circ} 51^{\prime} \mathrm{N}, 109^{\circ} 19^{\prime} \mathrm{E}\right)$. The experiment was conducted in pots at the nursery of the State Key Laboratory of Soil Erosion and Dryland Farming on the Loess Plateau, Yangling, Shaanxi Province, China $\left(34^{\circ} 12^{\prime} \mathrm{N}\right.$, $108^{\circ} 7^{\prime} \mathrm{E}$ ), which has a mean annual temperature of $12.9^{\circ} \mathrm{C}$, a maximum mean monthly temperature of $26.7^{\circ} \mathrm{C}$ in July, a minimum temperature of -1 to $-2^{\circ} \mathrm{C}$ in January, and a mean annual rainfall of $637.6 \mathrm{~mm}$.

The loessial soil used in the experiment was collected from the $0-20 \mathrm{~cm}$ soil layer in the natural grassland at ARS. The soil organic matter content was $3.6 \mathrm{~g} \mathrm{~kg}^{-1}$, and the total nitrogen $(\mathrm{N})$, phosphorus $(\mathrm{P})$, and potassium $(\mathrm{K})$ contents were $2.5,6.6$, and $1.9 \mathrm{~g} \mathrm{~kg}^{-1}$, respectively. The soil available $\mathrm{N}, \mathrm{P}$, and $\mathrm{K}$ contents were $19.62,50.78$, and $101.55 \mathrm{mg} \mathrm{kg}^{-1}$, respectively, and the soil $\mathrm{pH}$ value was 8.37 . The soil gravimetric moisture content at field capacity and wilting point were 20 and $4 \%$, respectively.

To ensure a sufficient nutrient supply for the plants, $\mathrm{N}$ and $\mathrm{P}$ were applied in each pot as basic fertilizers in the forms of $\mathrm{CON}_{2} \mathrm{H}_{4}(0.48 \mathrm{~g})$ and $\mathrm{KH}_{2} \mathrm{PO}_{4}(3.95 \mathrm{~g})$, respectively, and both were mixed uniformly with the soil during potting. Each cylindrical plastic pot $(20 \mathrm{~cm}$ diameter, $30 \mathrm{~cm}$ height $)$ was filled with $9 \mathrm{~kg}$ of the air-dried soil, and an open-end plastic pipe $(2 \mathrm{~cm}$ diameter) was inserted inside each pot adjacent to the inner wall to supply water at about $10 \mathrm{~cm}$ from the pot bottom. During rainy days, all the pots were covered by a rainout shelter.

\section{Species Combination Design}

A designed method of replacement series was used as reported by $\mathrm{Xu}$ et al. (2011b). The two species were grown at seven mixture ratios $(0: 12,2: 10,4: 8,6: 6,8: 4,10: 2$, and 12:0) of $B$. ischaemum to $L$. davurica with a density of 12 plants per pot on April 1, 2012. The seeds of each species were initially sown in 12 equally spaced holes, and in each hole, three to five seeds per species were dibbled. The schems of plant arrangement of both species in different mixture ratios per hole was followed as given by $\mathrm{Xu}$ et al. (2011b). Immediately after emergence, the seedlings were thinned to one plant per dibble, i.e., to 12 plants per pot. All the pots were initially well-watered to the field capacity during the seedling establishment till the tillering period of B. ischaemum.

\section{Watering Treatment}

In the semi-arid loess hilly-gully region on the Loess Plateau of China, B. ischaemum was the dominant species while $L$. davurica was the subordinate species in the natural grassland community (Xu et al., 2013). Their growth change and response to rainfall event variations greatly affected their co-existent community, thus in this study, the initiation of watering and re-watering treatments were carried out on the four key phonological periods of $B$. ischaemum, i.e., the tillering, heading, flowering, and mature period (Figure 1).

The watering treatments were initiated when seedlings of B. ischaemum had five leaves and L. davurica was still under branching. All the pots were divided into three groups on June 10, 2012, and each group was exposed to a watering regime as follows:

(1) High watering: maintain pot soil capacity (FC) at $80 \pm 5 \%(\mathrm{HW})$.

(2) Moderate watering: maintain pots at FC of $60 \pm 5 \%$ (MW).

(3) Low watering: maintain pots at FC of $40 \pm 5 \%$ (LW).

Then, three re-watering treatments were carried out during the three growth periods as follows: the heading period (July 10, 2012), flowering period (August 10, 2012), and mature

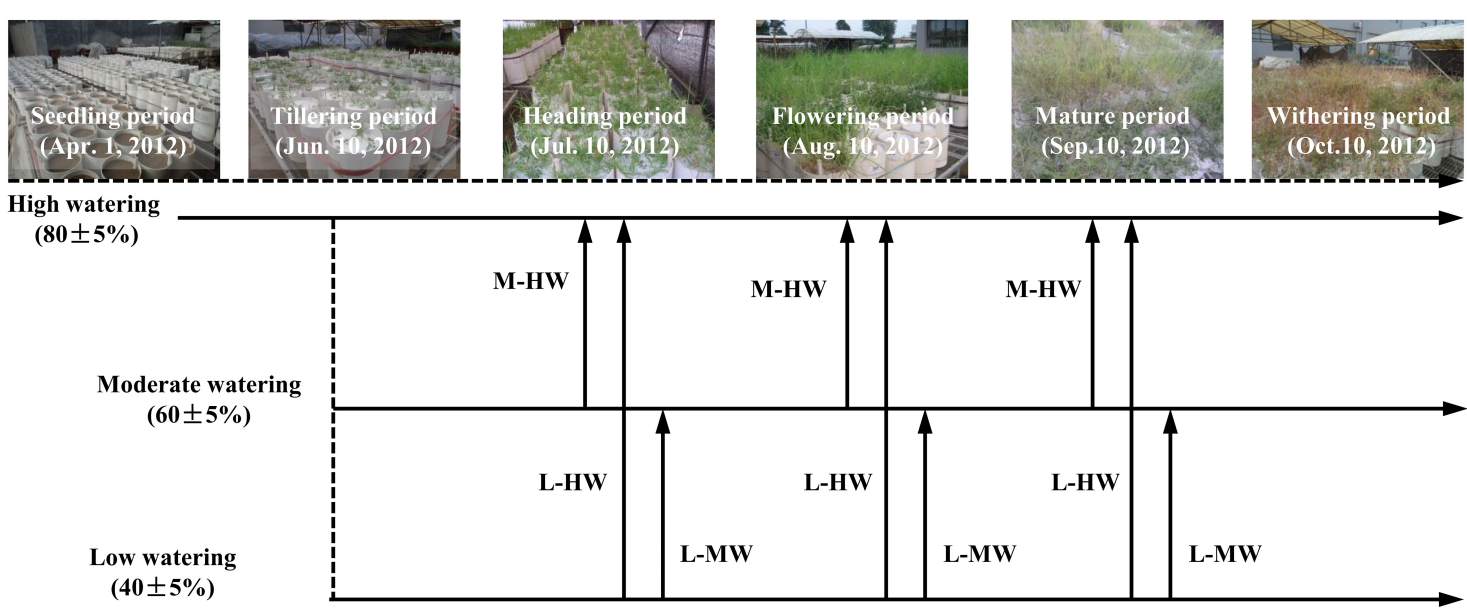

FIGURE 1 | The scheme of periodical soil watering treatments based on the growth periods of Bothriochloa ischaemum. High Watering (HW), $80 \pm 5 \%$ pot soil capacity (FC); Moderate Watering (MW), $60 \pm 5 \%$ FC; Low Watering (LW), $40 \pm 5 \%$ FC. Moderate to high watering (M-HW), soil water contents increased from MW to HW regime; Low to moderate or high watering (L-MW or L-HW), soil water contents increased from LW to MW or HW regime, respectively. 
TABLE 1 | Effects of soil watering, growth period, mixture ratio, and their interaction in the three-way ANOVA on the total biomass production and water use efficiency (WUE) of both species.

\begin{tabular}{|c|c|c|c|c|c|}
\hline \multirow[t]{2}{*}{ Source of variation } & \multirow[t]{2}{*}{$\mathrm{df}$} & \multicolumn{2}{|c|}{ Total biomass production } & \multicolumn{2}{|c|}{ Water use efficiency } \\
\hline & & $\boldsymbol{F}$ & $P$ & $\boldsymbol{F}$ & $P$ \\
\hline Soil watering (SW) & 2 & 2,638.659 & $<0.001$ & 113.215 & $<0.001$ \\
\hline Growth period (GP) & 2 & $1,924.063$ & $<0.001$ & 34.844 & $<0.001$ \\
\hline Mixture ratio (MR) & 6 & 386.590 & $<0.001$ & 509.001 & $<0.001$ \\
\hline $\mathrm{SW} \times \mathrm{GP}$ & 4 & 271.068 & $<0.001$ & 38.017 & $<0.001$ \\
\hline$S W \times M R$ & 12 & 54.662 & $<0.001$ & 13.156 & $<0.001$ \\
\hline $\mathrm{GP} \times \mathrm{MR}$ & 12 & 24.561 & $<0.001$ & 13.570 & $<0.001$ \\
\hline $\mathrm{SW} \times \mathrm{GP} \times \mathrm{MR}$ & 24 & 8.520 & $<0.001$ & 6.321 & $<0.001$ \\
\hline
\end{tabular}

Probabilities considered statistically significant are indicated in bold form.

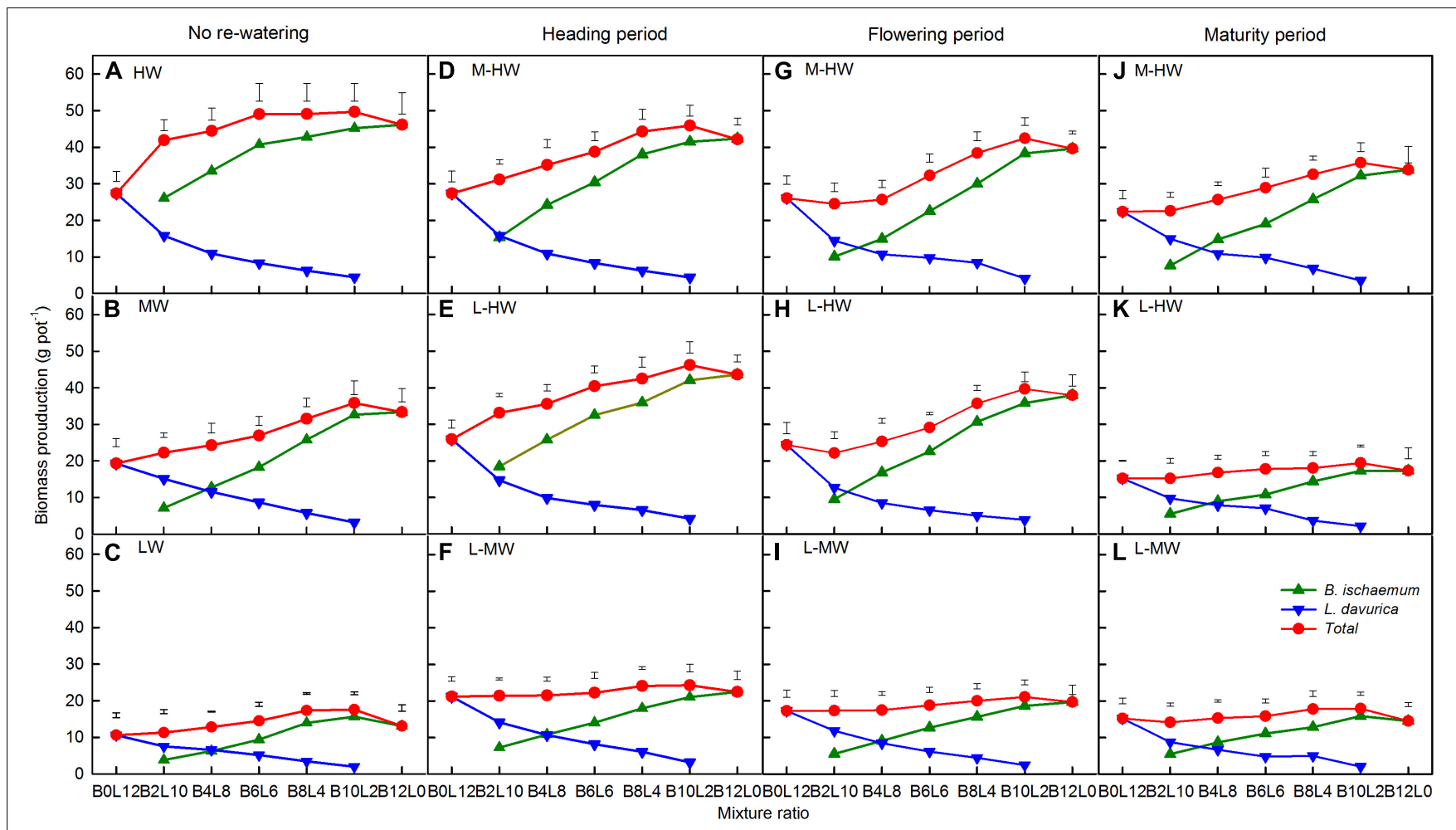

FIGURE 2 | (A-L) The total biomass production of $B$. ischaemum $(B)$ and Lespedeza davurica $(L)$ under the soil watering treatments during different growth periods within the replacement series. BiL $(i, j=0,2,4,6,8,10,12 ; i+j=12)$ in abscissa indicates the plant numbers of $B$. ischaemum to $L$. davurica in the mixtures; Vertical bars represent least significant difference (LSD) 0.05 values. Refer to Figure $\mathbf{1}$ for the codes of the water treatments.

period (September 12, 2012) of B. ischaemum. In each vegetative stage, the soil water contents were increased from MW to HW regime (referred to as $\mathrm{M}-\mathrm{HW}$ ), increased from $\mathrm{LW}$ to HW regime (referred to as L-HW), and increased from LW to $\mathrm{MW}$ regime (referred to as L-MW) through re-watering, respectively (Figure 1).

For the nursing of the desired water regimes, plant transpiration was measured by weighing each pot every day at 18:00 h, and each pot was watered via the plastic pipes to maintain the target water regime. To reduce soil compaction caused by watering and soil evaporation, $40 \mathrm{~g}$ of perlite was spread on the soil surface of each pot. The levels of the soil water content after re-watering were maintained until the end of the growing season, on October 10, 2012.

There were a total of 420 pots: 7 (mixture ratios) $\times 12$ [3 $($ re-watering $) \times 3$ (growth period $)+3$ (no re-watering $)] \times 5$ (replications). All the pots were arranged in a completely random design within the replications for each treatment.

\section{Shoot and Root Biomass Production}

At the end of the growth season on October 10,2012, all the pots of each treatment were harvested and the shoot and root parts of each species were separated. The soil from roots was removed by washing with water and the shoot and root biomass were 
TABLE 2 | Effects of soil watering, growth period, mixture ratio, and their interaction in the three-way ANOVA on the biomass production and root/shoot ratio (RSR) of both species.

\begin{tabular}{|c|c|c|c|c|c|c|c|c|c|}
\hline \multirow[t]{3}{*}{ Source of variation } & \multirow[t]{3}{*}{ df } & \multicolumn{4}{|c|}{ Bothriochloa ischaemum } & \multicolumn{4}{|c|}{ Lespedeza davurica } \\
\hline & & \multicolumn{2}{|c|}{ Biomass production } & \multicolumn{2}{|c|}{ Root/shoot ratio } & \multicolumn{2}{|c|}{ Biomass production } & \multicolumn{2}{|c|}{ Root/shoot ratio } \\
\hline & & $\boldsymbol{F}$ & $P$ & $\boldsymbol{F}$ & $P$ & $\boldsymbol{F}$ & $P$ & $\boldsymbol{F}$ & $P$ \\
\hline Soil watering (SW) & 2 & 520.772 & $<0.001$ & 35.333 & $<0.001$ & 230.583 & $<0.001$ & 167.754 & $<0.001$ \\
\hline Growth period (GP) & 2 & 394.826 & $<0.001$ & 2.485 & 0.088 & 220.371 & $<0.001$ & 355.237 & $<0.001$ \\
\hline Mixture ratio (MR) & 5 & 399.734 & $<0.001$ & 3.764 & 0.003 & 1978.953 & $<0.001$ & 4.974 & $<0.001$ \\
\hline $\mathrm{SW} \times \mathrm{GP}$ & 3 & 119.527 & $<0.001$ & 65.012 & $<0.001$ & 37.833 & $<0.001$ & 25.060 & $<0.001$ \\
\hline$S W \times M R$ & 10 & 19.353 & $<0.001$ & 3.678 & $<0.001$ & 18.774 & $<0.001$ & 6.083 & $<0.001$ \\
\hline $\mathrm{GP} \times \mathrm{MR}$ & 10 & 7.123 & $<0.001$ & 5.590 & $<0.001$ & 25.439 & $<0.001$ & 2.707 & 0.005 \\
\hline $\mathrm{SW} \times \mathrm{GP} \times \mathrm{MR}$ & 15 & 2.197 & 0.010 & 3.311 & $<0.001$ & 7.198 & $<0.001$ & 1.913 & 0.029 \\
\hline
\end{tabular}

Probabilities considered statistically significant are indicated in bold form.

determined after drying at $75^{\circ} \mathrm{C}$ for $48 \mathrm{~h}$ in an air-dried oven. The root/shoot ratio (RSR) was calculated as the ratio of root to shoot dry biomass.

\section{Water Use Efficiency}

The daily evapotranspiration was obtained by weighing the pots daily at 18:00 h. Three identical pots filled with soil but without plants for each water treatment were used to estimate the soil evaporation, and they were watered individually to the desired regime as those with plants. The estimate of the soil evaporation was subtracted from evapotranspiration to calculate the transpiration of both species. So, WUE was defined as the amount of the total biomass produced per unit volume of the water transpired.

\section{Competitive Indices}

Several indicators for species interaction have been used in intercropping research. These indicators can be divided into three categories: quantification of competition intensity, the effect of competition, and the outcome of competition (Weigelt and Jolliffe, 2003). Relative competition intensity (RCI) and competitive balance (CB) were employed for studying the intensity of competition, and RYT was employed for analyzing the competition effects. These indexes have been commonly used in experimental designs involving series planting replacements, and they were calculated from the dry biomass of each species and their various proportions within the replacement series.

Relative competition intensity was used to compare the intra- and interspecific competition of the two species (Sammul et al., 2000). The equal intra- and interspecific competition are indicated by $\mathrm{RCI}=0$, and a positive value indicates that the interspecific competition is high, while a negative value means high intraspecific competition. The RCI was calculated as follows:

$$
R C I=\left(Y_{B B} \times Z_{B L}-Y_{B L}\right) /\left(Y_{B B} \times Z_{B L}\right)
$$

where $Y_{B B}$ is the biomass production of $B$. ischaemum in monoculture and $\mathrm{Y}_{L L}$ is the biomass production of $L$. davurica in monoculture. $Y_{B L}$ or $Y_{L B}$ is the biomass production of B. ischaemum or $L$. davurica in their mixtures. $Z_{B L}$ or
$\mathrm{Z}_{L B}$ is mixture proportions of $B$. ischaemum or $L$. davurica in their mixtures.

Competitive balance was another index that was used to quantify the relative competitive ability of each species in the mixtures (Wilson, 1988). A CB of 0 indicates no competition or equal competitive abilities between the two species, and a positive value indicates that $B$. ischaemum has a higher competitive ability than $L$. davurica, while a negative value indicates that $L$. davurica was the better competitor. The CB was calculated as follows:

$$
C B=\ln \left(Y_{B L} / Y_{L B}\right)
$$

The relative yield total was estimated to assess the biological efficiency of the intercropping system (Williams and Mccarthy, 2001). If the RYT $=1$, then the two species have equal demands for the same limiting resource. Values greater than 1 indicate that the mixtures are advantageous for biomass production compared with monocultures, while less than 1 indicates mutual antagonism. The RYT was calculated as follows:

$$
R Y T=Y_{B L} / Y_{B B}+Y_{B L} / Y_{L L}
$$

\section{Statistical Analysis}

In the study, each treatment had five repetitions, and three replications of each treatment were randomly selected for sampling. The data were checked using the normality (ShapiroWilk's test) and homogeneity of variances (Levene's test) before analysis and were expressed as the mean \pm SE of the three replications. The differences in the mean values of the plant biomass, WUE, RSR, and each competitive indices were compared among treatments using a one-way ANOVA followed by Tukey's honestly significant difference (HSD) tests, and the statistical significance was set at $P<0.05$. Three-way ANOVA was used to evaluate the interactive effects of soil watering, growth period, and mixture ratio on biomass production, WUE, $\mathrm{RSR}$, and competitive indices ( $\mathrm{RYT}, \mathrm{RCI}_{B}, \mathrm{RCI}_{L}$, and $\mathrm{CB}$ values) of the species. The least significant differences (LSD) $(P=0.05)$ were calculated for the mean separations and are shown in the figures. All statistical analyses of the data were conducted using SPSS 17.0 (IBM, Armonk, NY, United States). 


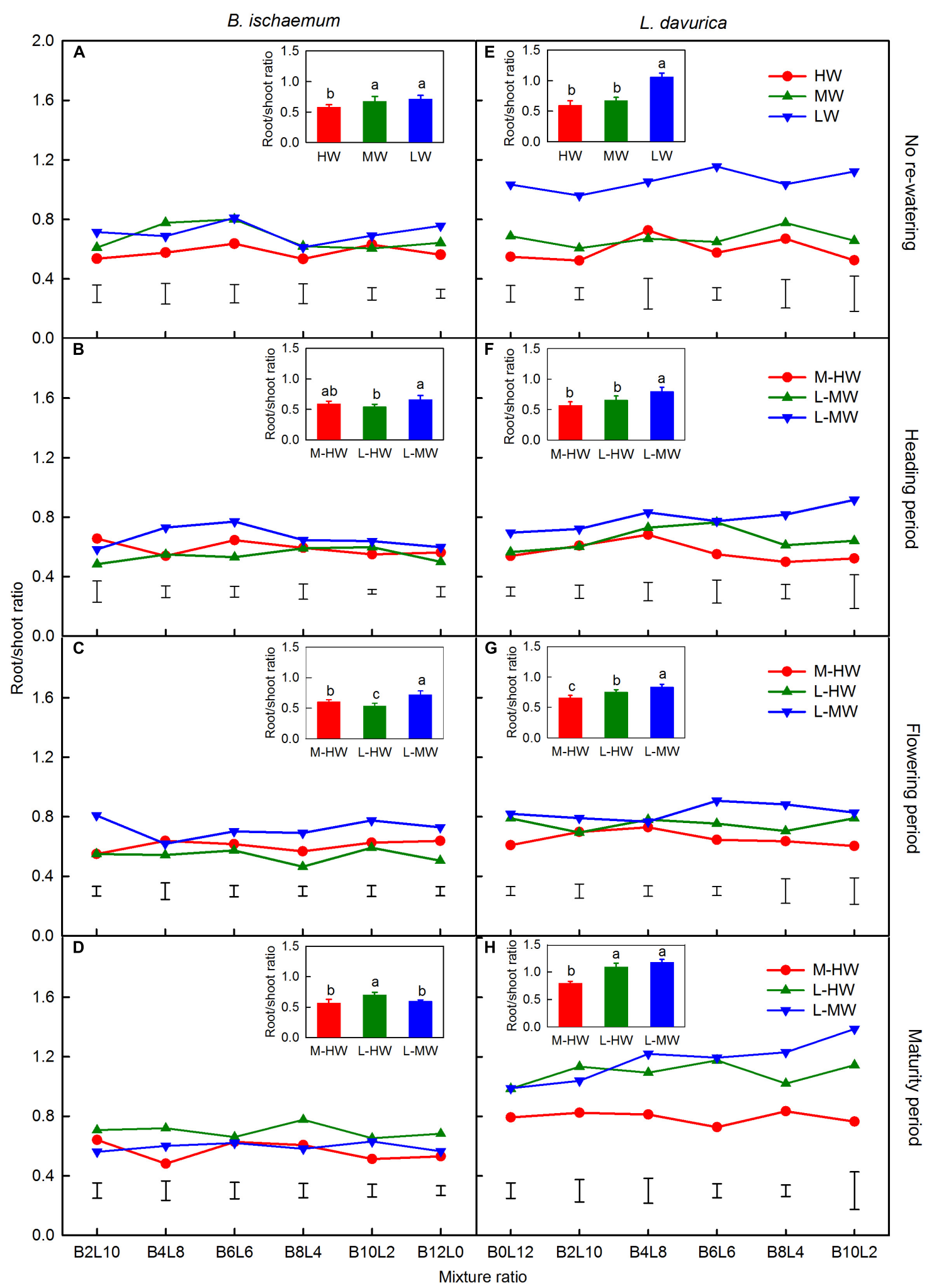

FIGURE 3 | (A-H) The root/shoot ratio (RSR) of $B$. ischaemum (B) and $L$. davurica $(\mathrm{L})$ under the soil watering treatments during different growth periods within the replacement series. BiLj $(i, j=0,2,4,6,8,10,12 ; i+j=12)$ in abscissa indicates the plant numbers of $B$. ischaemum to $L$. davurica in the mixtures; Vertical bars represent LSD 0.05 values. The values in the small histogram are the mean across all mixture ratios, and the columns and bars indicate the mean \pm SE, the letters are used for the comparisons between different water treatments by LSD test $(P<0.05)$. Refer to Figure $\mathbf{1}$ for the codes of the water treatments. 


\section{RESULTS}

\section{Biomass Production}

Increasing the soil water availability, growth period, mixture ratio, and their interactions significantly affected the total biomass production (Table 1). The total biomass production in each species was significantly increased as the proportion of $B$. ischaemum was increased in the mixture ratios, and the highest biomass production was at the 10:2 mixture ratio in most cases (Figure 2). Among the seven mixtures, B. ischaemum showed a higher biomass production at the 10:2 mixture ratio and in the monoculture (i.e., 12:0), while the L. davurica monoculture had a higher biomass production (Figure 2).

Under each watering regime, $B$. ischaemum had a higher biomass production than $L$. davurica at the equal mixture ratio (i.e., 6:6), except when re-watering from L-MW at the heading and maturity periods (Figure 2). The curves of the replacement series diagrams of biomass production in B. ischaemum were concave, while those in L. davurica were convex, and their lines intersected to the left of the 6:6 mixture ratio, i.e., the proportion of $B$. ischaemum was lower in mixtures (Figure 2).

Compared with MW, the average total biomass production across all mixture ratios was increased by about 40.4 and $18.3 \%$ when the soil water increased from $\mathrm{M}-\mathrm{HW}$ at the heading and flowering periods, respectively (Figure 2). Those values were significantly increased by about $21.7-166.1 \%$ when the soil water increased from L-HW at each period and significantly increased by about 60.2 and $33.1 \%$ when the soil water increased from L-MW at the heading and flowering stages, compared with the LW treatment (Figure 2).

\section{Root/Shoot Ratio}

Increasing the soil water availability, growth period, mixture ratio, and their interactions significantly affected the RSR of both species, except for the effect of the growth period (Table 2). There were no significant changes in the RSR of both species across the different mixture ratios under the watering regimes, but the increase in soil water availability significantly decreased the RSR in most cases (Figure 3). The RSR in B. ischaemum ranged from 0.46 to 0.81 across mixture ratios under watering regimes, while the RSR in L. davurica ranged from 0.50 to 1.39 (Figure 3).

For B. ischaemum, the average RSR decreased by about $10.3-$ $16.2 \%$ when the soil water increased from M-HW compared with MW (Figure 3). Compared with LW, those values decreased by 5.1 and $18.7 \%$ under MW and HW, decreased by $1.7-24.5 \%$ when the soil water increased from L-HW and decreased by 7 and $16.7 \%$ when the soil water increased from L-MW, respectively, at the heading and maturity stages (Figure 3).

For L. davurica, the average RSR was decreased by 15.8 and $3.2 \%$ when the soil water increased from $\mathrm{M}-\mathrm{HW}$ at the heading and flowering stages, compared with the MW level (Figure 3). Compared with LW, the RSR was decreased by $21.5-38.4 \%$ when the soil water increased from L-MW and - HW at the heading and flowering stages, respectively, and increased by $11-17.5 \%$ when soil water increased from L-MW and - HW at the maturity stage (Figure 3). 


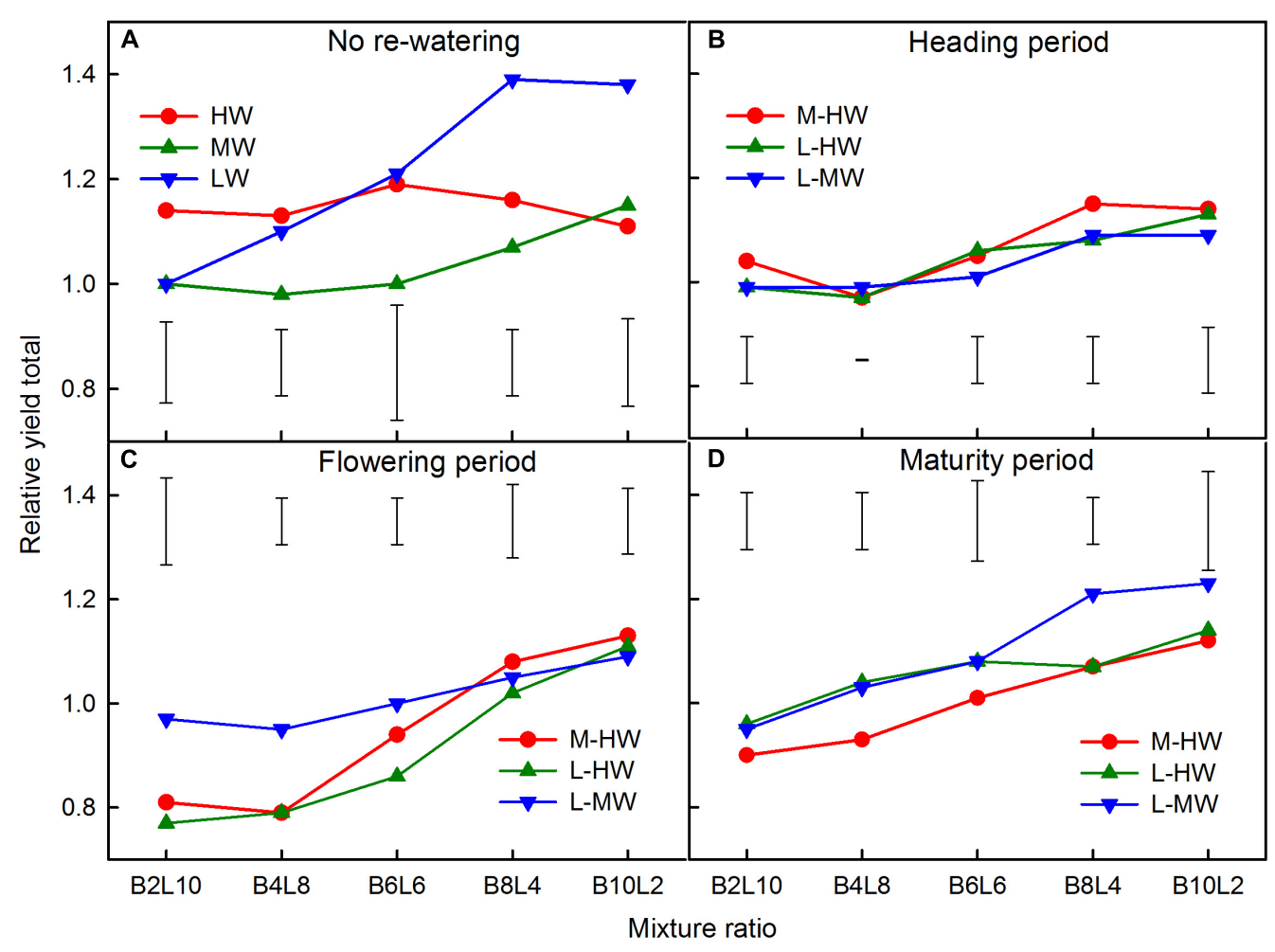

FIGURE 4 | (A-D) The relative yield total (RYT) for the total biomass production of $B$. ischaemum $(B)$ and $L$. davurica $(L)$ in the mixtures under the soil watering treatments during different growth periods. BiL $j(i, j=0,2,4,6,8,10,12 ; i+j=12)$ in abscissa indicates the plant numbers of $B$. ischaemum to $L$. davurica in their mixtures; Vertical bars represent LSD 0.05 values. Refer to Figure $\mathbf{1}$ for the codes of the water treatments.

\section{Relative Yield Total}

Increasing the soil water availability, growth period, mixture ratio, and their interactions significantly affected the RYT in the mixtures, except for the effect of the interaction of the soil watering and mixture ratio (Table 3). The RYT significantly decreased with the increase in the soil water availability but increased gradually as the proportion of $B$. ischaemum increased in the mixtures, except under HW (Figure 4). The average RYT across all water treatments at the 2:10 and 4:8 mixture ratios were all less than 1 , indicating that there was a similar mutual antagonism between both species in such mixture ratio, while the relatively higher values obtained at the 10:2 mixture ratio, indicate that the mixed planting of both species in the 10:2 mixture ratio was more advantageous for biomass production compared with monocultures (Figure 4).

Compared with the RYT under MW, the average RYT was decreased by 8.7 and $3.3 \%$ when the soil water increased from $\mathrm{M}-\mathrm{HW}$ at the flowering and maturity periods, respectively, but increased by $2.9 \%$ when the soil water increased from M-HW at the heading period (Figure 4). Compared with LW, those values decreased by $9.8-25.4 \%$ when the soil water increased from L-MW or -HW at each period (Figure 4).

\section{Relative Competition Intensity}

Increasing the soil water availability, growth period, mixture ratio, and their interactions significantly affected the RCI in the mixtures, except for the effect of the interactions of the soil watering and mixture ratio (Table 3). The RCI value of B. ischaemum was negative, indicating that the effects of the intraspecific competition were stronger than the interspecific competition. The RCI of $L$. davurica was greater than zero, indicating that the interspecific competition was stronger than the intraspecific competition (Figure 5). Under each watering regime, the RCI of both species was increased gradually as their proportions increased in the mixtures (Figure 5).

For B. ischaemum, the average RCI decreased by $44.3-260.8 \%$ when the soil water increased from M-HW, compared with MW (Figure 5). Compared with LW, those values were decreased by 21.6 and $20.8 \%$ when the soil water increased from L-HW at the heading and maturity periods, respectively, but increased by $17.8-70.1 \%$ when the soil water increased from L-MW and -HW (Figure 5).

For $L$. davurica, the average RCI values increased by $48-$ $128 \%$ when the soil water availability increased from M-HW (Figure 5). Compared with LW, the RCI values were increased by $48.5-411.4 \%$ when the soil water increased from L-MW or -HW (Figure 5).

\section{Competitive Balance}

Increasing the soil water availability, growth period, mixture ratio, and their interactions significantly affected the $\mathrm{CB}$ of B. ischaemum when calculated from the total, shoot, or root 

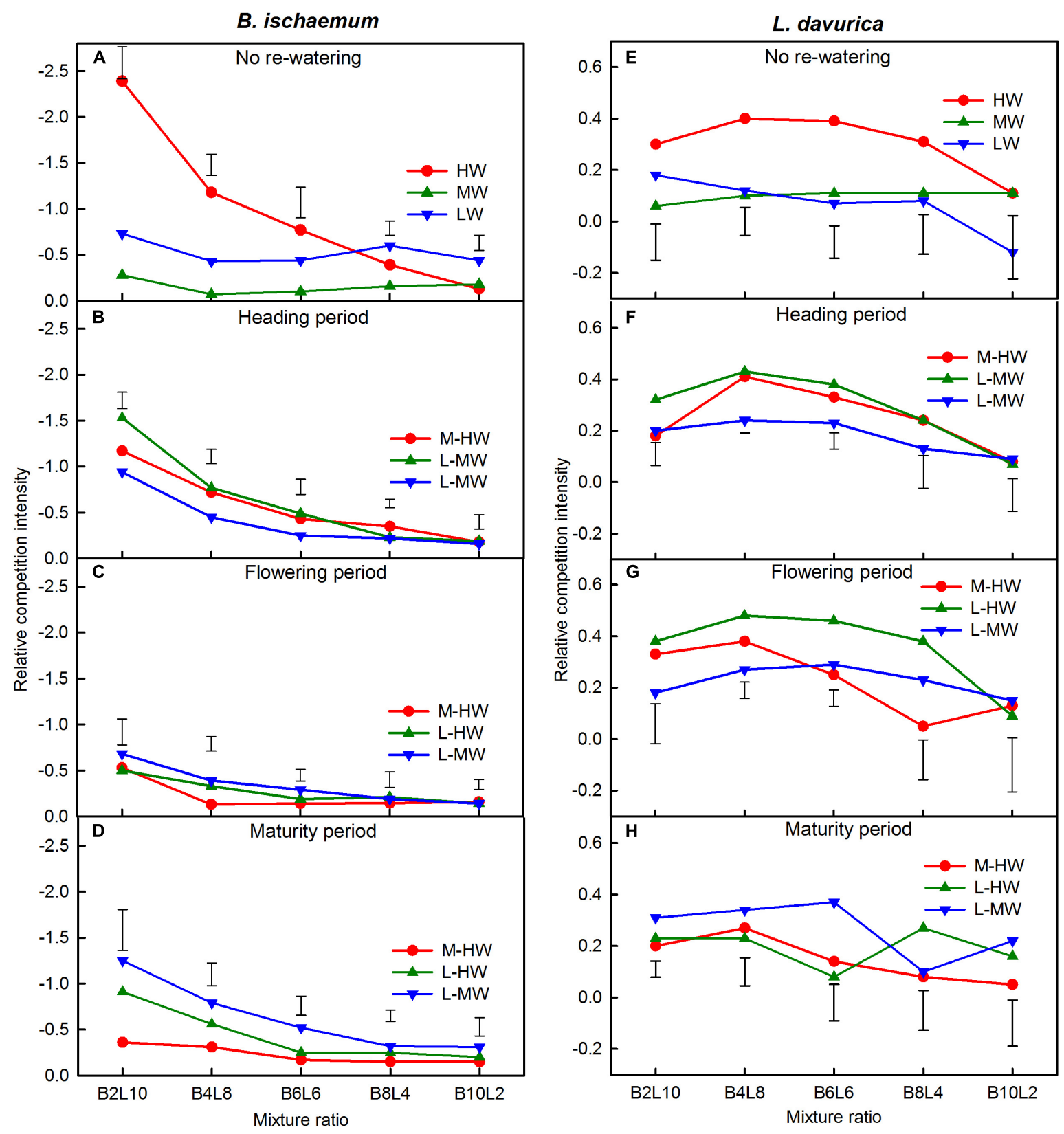

FIGURE 5 | (A-H) The relative competition intensity $(\mathrm{RCl})$ for the total biomass of $B$. ischaemum $(B)$ and $L$. davurica $(L)$ in the mixtures under the soil watering treatments during different growth periods. BiLj $(i, j=0,2,4,6,8,10,12 ; i+j=12)$ in abscissa indicates the plant numbers of $B$. ischaemum to $L$. davurica in their mixtures; Vertical bars represent LSD 0.05 values. Refer to Figure $\mathbf{1}$ for the codes of the water treatments.

biomass (Table 3). The $\mathrm{CB}$ of $B$. ischaemum calculated from the total, shoot, or root biomass increased gradually as its proportion increased in the mixtures, and the relatively higher values were obtained at the 10:2 mixture ratio, indicating that the competitiveness of $B$. ischaemum was stronger (Figure 6).

The $\mathrm{CB}$ of $B$. ischaemum calculated from the total, shoot, or root biomass was significantly increased under increased soil water availability, especially when calculated based on the shoot biomass (Figure 6). The average $\mathrm{CB}$ values in $B$. ischaemum increased up to 2.04 times when calculated from the total biomass, ranged from 20.6 to $153.5 \%$ when calculated from the shoot biomass, and ranged from 0 to $160.1 \%$ when calculated from the root biomass (Figure 6).

\section{Water Use Efficiency}

Increasing soil water availability, growth period, mixture ratio, and their interactions significantly affected the WUE of both species (Table 1). The WUE was significantly increased as the proportion of $B$. ischaemum increased while $L$. davurica decreased in the mixture ratios (Figure 7). Across all the watering 


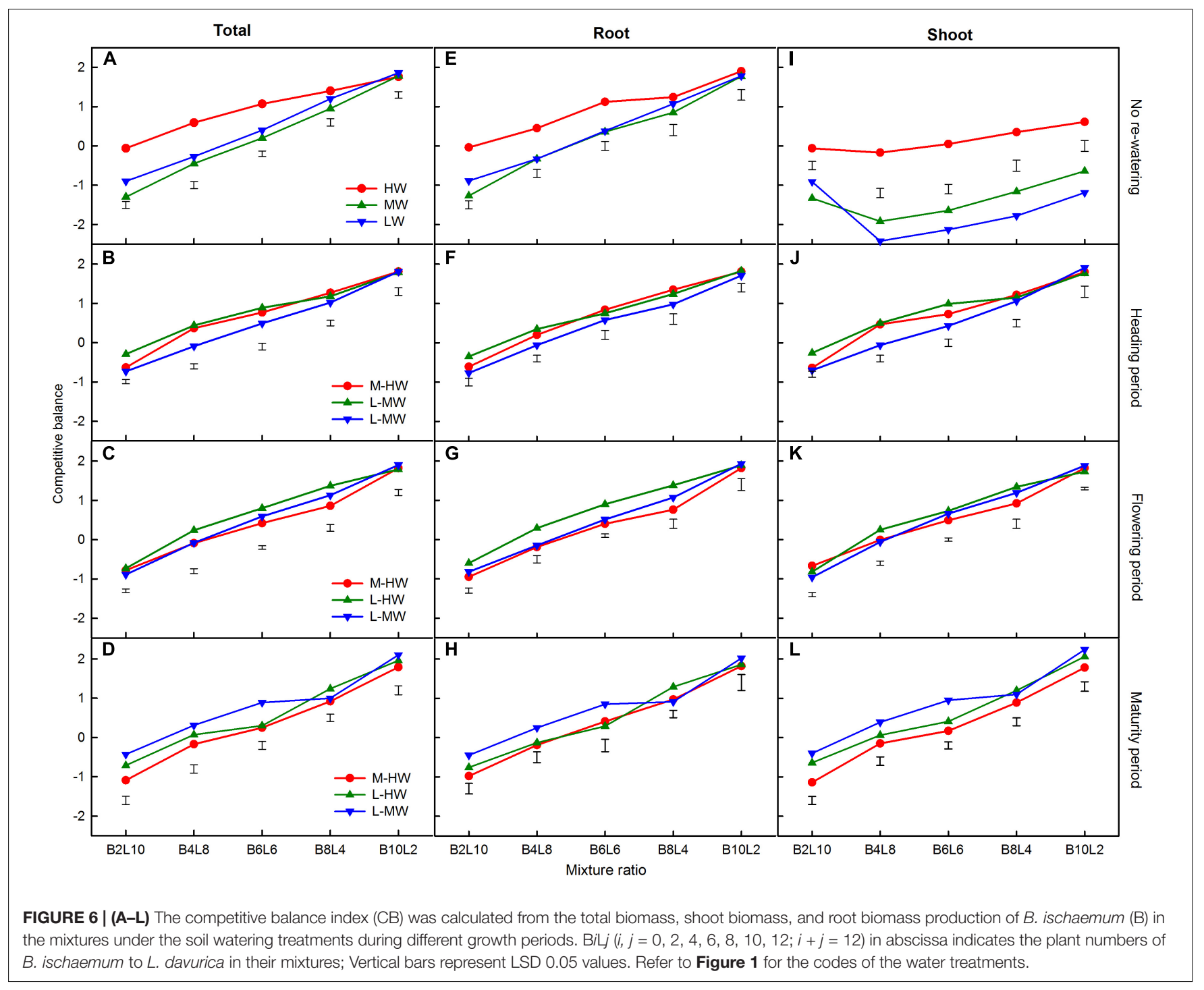

regimes, the WUE was the highest at the 10:2 mixture ratio and $B$. ischaemum under monoculture, while the lowest WUE was in L. davurica under monoculture (Figure 7).

The WUE increased under the increasing soil water availability, and the average WUE across all mixtures ratios and in both species increased by $0-8.6 \%$ when the soil water increased from $\mathrm{M}-\mathrm{HW}$ at each period (Figure 7). Compared with LW levels, the corresponding values increased by $0-43.0 \%$ when the soil water increased from L-MW or HW (Figure 7).

\section{DISCUSSION}

\section{Biomass Allocation and Water Use in Response to Soil Watering}

Climate change has a strong impact on the availability and variability of water resources. It is expected that climate change will alter the seasonal distribution, frequency, and intensity of rainfall events in the semi-arid regions, which may result in fewer and heavier rainfall events (IPCC, 2014; Miao et al., 2016). In this study, the increasing soil water availability during the growing season improved the biomass of two co-occurring species of $B$. ischaemum and L. davurica, but larger increases occurred in the perennial herbaceous grass $B$. ischaemum, which largely contributed to the total biomass production when in mixtures (Figure 2). Increasing the soil water availability and planting mixture affected the biomass of both species, but the biomass production of $B$. ischaemum in the mixtures at the heading and flowering periods was much higher than in the monoculture, while $L$. davurica showed opposite patterns (Figure 2). This indicates that there was a positive additive effect of periodical re-watering and planting mixture on the biomass production of B. ischaemum during its early growing season (Xu et al., 2013; Wang et al., 2018). For L. davurica, the promoting effect of rewatering on its biomass can be suppressed by mixed planting and due to that, its growth was restrained in the mixtures (Xu et al., 2011a,b). Therefore, it can be predicted that the abundance and biomass of $B$. ischaemum will significantly increase in relatively 


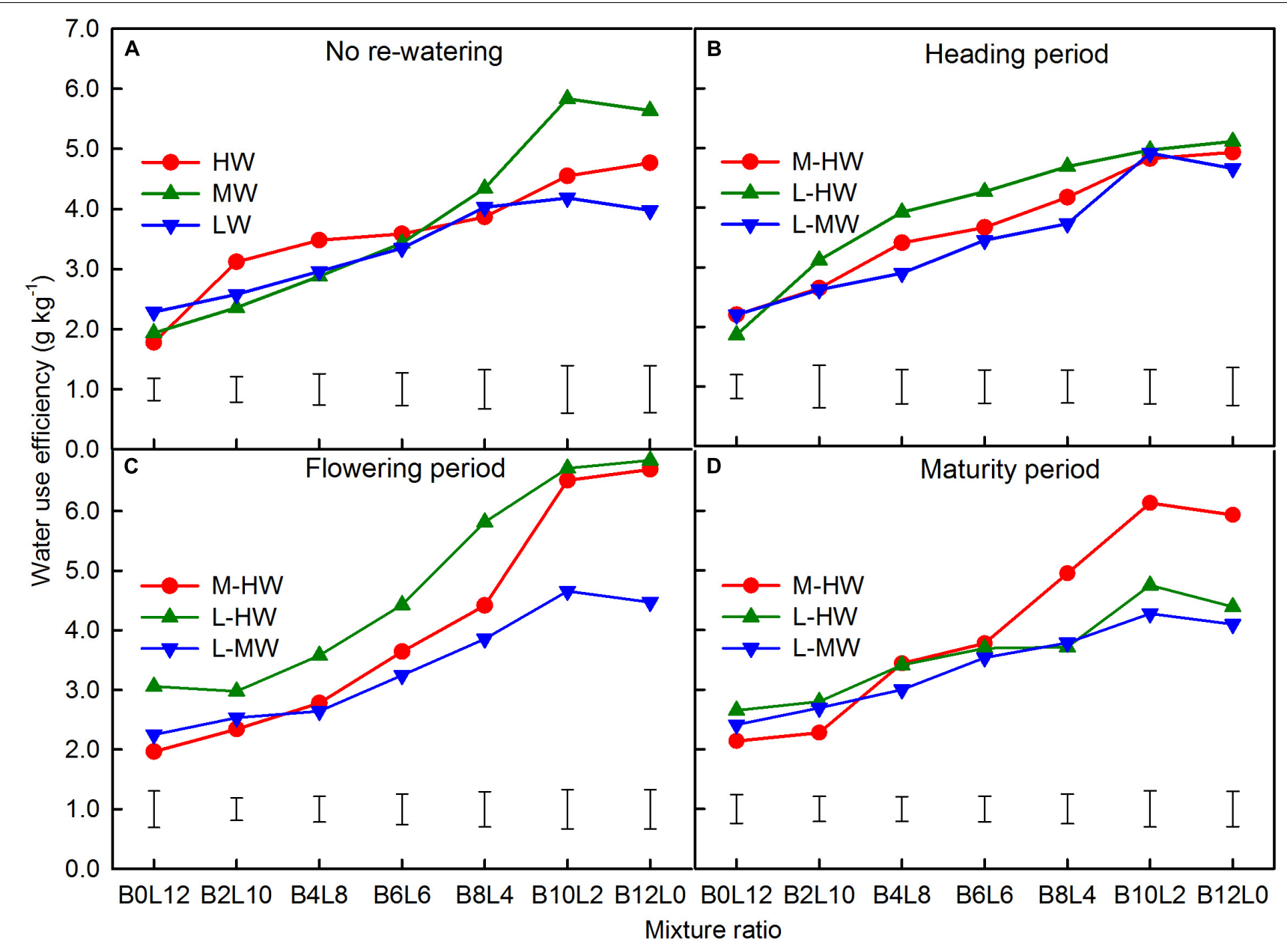

FIGURE 7 | (A-D) The water use efficiency (WUE) based on the total biomass production and water transpired by $B$. ischaemum (B) and $L$. davurica (L) under the soil watering treatments during different growth periods within the replacement series. BiL $j(i, j=0,2,4,6,8,10,12 ; i+j=12)$ in abscissa indicates the plant numbers of $B$. ischaemum to $L$. davurica in the mixtures; Vertical bars represent LSD 0.05 values. Refer to Figure $\mathbf{1}$ for the codes of the water treatments.

wet seasons, years, or regions, compared with L. davurica (Peng et al., 2013; Niu et al., 2016).

Previous research indicated that mixed planting enhanced the photosynthetic performance of $B$. ischaemum in the heading and flowering stages, while those of $L$. davurica were improved only in the mature stage (Xu et al., 2014, 2017). In both species at the heading and flowering periods, the total biomass production was higher when the soil water increased from L-HW than increased from L-MW, but there were no significant differences between the soil water increased from M-HW and L-HW. These indicate that the re-watering intensity or increase in soil water availability from lower antecedent soil water availability were larger, leading to the greater community biomass production of the two species, especially at the early growing season (Xiong et al., 2017; Wang et al., 2018).

Increasing the soil water availability reduced the RSR in both species, with a smaller RSR value in B. ischaemum than in $L$. davurica. This was due to the synchronous increase in the shoot and root biomass, and such difference may enhance the competitive ability of $B$. ischaemum for above- and belowground resources under increasing soil water availability (Liu et al., 2012; Foxx and Florian, 2019). However, there was no clear changing trend in the biomass allocation of both species among mixture ratios under each water regime, indicating that both species maintained relatively stable root and shoot biomass allocation patterns in response to the altered mixture ratio and soil water regimes (Xu et al., 2011a; Zhang et al., 2017).

In the intercropping systems, the WUE was influenced by the plant density and species proportion (Xu et al., 2013; Ren et al., 2017). In this study, the WUE was increased as the proportion of $B$. ischaemum increased in the mixtures, and the highest WUE was obtained at the 10:2 mixture ratio of B. ischaemum and L. davurica (Figure 7). Across the mixture ratio and water regimes, the highest WUE was obtained in the 10:2 mixture ratio of B. ischaemum to L. davurica, which indicated that there may exist more mutual beneficial effects between the two species (Lithourgidis et al., 2011; Xu et al., 2013), and such mixture ratio is recommended for the use 
of $B$. ischaemum and $L$. davurica in the artificial grassland constructions in the region.

\section{Plant-Plant Interactions in Response to Varying Mixture Ratios}

Ecological theory predicts that productivity will be higher in mixtures if species use environmental resources differently in both time or space (Banik et al., 2000; Wilsey, 2010). The RYT gives an accurate assessment of the greater biological efficiency of the intercropping situation (Williams and Mccarthy, 2001). The average RYT across the water regimes at the 6:6, 8:4, and 10:2 mixture ratios were 1.04-1.15 (Figure 4). The results indicate that mixed planting will improve the efficient use of land and environmental resources if the proportion of B. ischaemum is greater than $50 \%$ in the mixtures (Gao et al., 2009; Lithourgidis et al., 2011). Similar studies on legume and non-legume intercropping systems have given RYT values greater than 1 , which have been attributed to the differences in the root and shoot characteristics, and the use of different $\mathrm{N}$ sources (Lithourgidis et al., 2011; Manasa et al., 2020). Results have shown that the RYT of both species in the mixed planting systems were greatly affected by their mixture ratios than the increasing soil water availability (Table 3 and Figure 4), which indicated that the ratio of the proportion of both species within the replacement series could affect the efficiency of intercropping systems significantly (Aynehband and Behrooz, 2011).

According to our previous studies, the intersection point of both biomass curves at the 6:6 mixture ratio in the replacement series diagram, suggests the equal competitive abilities between both species (Xu et al., 2011a, 2013). As shown in Figure 2, the biomass production curves of the two species intersect to the left of the 6:6 mixture ratio under each water treatment, indicating that $B$. ischaemum was more competitive than $L$. davurica in most cases, which also showed the frequency of the occurrence of interspecific competition between the two species in the mixtures (Foxx and Florian, 2019). Our results suggest that the growth of $L$. davurica appeared to be adversely affected by the competition from $B$. ischaemum, likely because the latter was more competitive in the mixtures under periodical soil water availability (Xu et al., 2011a,b).

Moreover, the species with positive $\mathrm{CB}$ values indicate its dominance and higher competitive ability than the component species in the intercropping systems (Wilson, 1988; Ghosh, 2004), thus, B. ischaemum was the dominant species with higher competitiveness when its proportion was greater than $50 \%$ in the mixtures with $L$. davurica (Figure 6). The higher competition of the grass over the legume species is likely to be explained by its extensive fine root system (Eekeren et al., 2009; Xu et al., 2011b). Moreover, the results obtained indicated the intensification in the shoot competition of $B$. ischaemum under high watering, which was ascribed to the increased $\mathrm{CB}$ values calculated from the shoot biomass (Figure 6). This was consistent with previous studies showing that the shoot competition of grassland species was more intense than the root under higher water availability (Lamb et al., 2007). The $\mathrm{CB}$ values of $B$. ischaemum increased as its proportion in the mixtures increased, indicating that its dominance was improved as its density was promoted (Dolijanovic et al., 2013; Yu et al., 2016).

The strong intraspecific competition in B. ischaemum and high interspecific competitive pressure in $L$. davurica indicates that the growth of $L$. davurica was restrained in the mixtures (Jolliffe et al., 1984; Xu et al., 2013). The gradual increase in the RCI in both species across all the watering regimes as their proportions increased in the mixtures, suggests that B. ischaemum faced lower intraspecific competitive pressure as its ratio increased in mixtures (García-Cervigón et al., 2013). Previous research also showed that the intraspecific competition between individuals of $B$. ischaemum was higher than the interspecific competition, and the competition between both species for soil $\mathrm{P}$ became intense when the soil $\mathrm{N}$ availability increased (Xu et al., 2013). The RCI values of both species decreased to zero as the proportions of $B$. ischaemum increased in mixtures, and the more stable ratio of the two species was obtained at 10:2 as their intra-and interspecific competitiveness tended to be equal (Jolliffe et al., 1984; Geijzendorffer et al., 2011).

\section{CONCLUSION}

The biomass production, WUE, and competitive ability of the two native species in controlled mixtures were affected by changes in soil water availability. Soil watering at the early growth period promoted the biomass of $B$. ischaemum, and this herbaceous grass, hence, has given a higher contribution to the biomass production in the mixtures. The dominant position and competitiveness of $B$. ischaemum in the mixtures was increased with soil watering as supported by the positive $\mathrm{CB}$ values. The results clearly showed that $B$. ischaemum was the dominant species, and its proportion affected the complementarity effect of the two species in the mixtures. Furthermore, our results provided increasing evidence that B. ischaemum responded more positively to the increasing soil water availability than $L$. davurica, and perhaps ultimately, the abundance of this grass species in the region could increase in relatively wet seasons, years, or if rainfalls become more frequent in the future with climate change. The 10:2 proportion for intercropping $B$. ischaemum with $L$. davurica could be recommended as the most efficient species individuals combination for establishing artificial grasslands in the region when using those two native species, in terms of the higher biomass production and WUE, and the higher RYT and lower RCI values.

\section{DATA AVAILABILITY STATEMENT}

The original contributions presented in the study are included in the article/supplementary material, further inquiries can be directed to the corresponding author. 


\section{AUTHOR CONTRIBUTIONS}

$\mathrm{WX}, \mathrm{XD}$, and $\mathrm{BX}$ conceived and designed the experiments. WX conducted the experiments. WX and BX analyzed the data and wrote the manuscript with major inputs from all coauthors. JP and YC provided critical comments and revised the manuscript. All authors contributed to the article and approved the submitted version.

\section{REFERENCES}

Adler, P. B., Smull, D., Beard, K. H., Choi, R. T., Furnis, T., Kulmatiski, A. et al. (2018). Competition and coexistence in plant communities: intraspecific competition is stronger than interspecific competition. Ecol. Lett. 21, 13191329. doi: $10.1111 /$ ele. 13098

Aynehband, A., and Behrooz, M. (2011). Evaluation of cereal-legume and cereal-pseudocereal intercropping systems through forage productivity and competition ability. Am. Eur. J. Agric. Environ. Sci. 10, 675-683.

Báez, S., Collins, S. L., Pockman, W. T., Johnson, J. E., and Small, E. E. (2013). Effects of experimental rainfall manipulations on chihuahuan desert grassland and shrubland plant communities. Oecologia 172:1117. doi: 10.1007/s00442012-2552-0

Bai, Y. F., Han, X. G., Wu, J. G., Chen, Z. Z., and Li, L. H. (2004). Ecosystem stability and compensatory effects in the Inner Mongolia grassland. Nature 431, 181-184. doi: 10.1038/nature02850

Banik, P., Sasmal, T., Ghosal, P. K., and Bagchi, D. K. (2000). Evaluation of mustard (Brassica compestris var. Toria) and legume intercropping under 1:1 and 2:1 row-replacement series system. Agron. Crop Sci. 8, 9-14. doi: 10.1046/j.1439037X.2000.00388.x

Bhandari, J., Pan, X., and Bijaya, G. C. D. (2015). Spatial and seasonal variation in rain use efficiency in semiarid grasslands of Inner Mongolia. Adv. Meteorol. 2015, 1-7. doi: 10.1155/2015/917415

Dolijanovic, Z., Oljaca, S., Kovacevic, D., Simic, M., and Jovanovic, Z. (2013). Dependence of the productivity of maize and soybean intercropping systems on hybrid type and plant arrangement pattern. Genetika 45, 135-144. doi: 10.2298/gensr1301135d

Eekeren, N., Liere, D., Vries, F., Michiel, R., Goede, R., and Brussaard, L. (2009). A mixture of grass and clover combines the positive effects of both plant species on selected soil biota. Appl. Soil Ecol. 42, 254-263. doi: 10.1016/j.apsoil.2009.04. 006

Fay, P. A. (2009). Precipitation variability and primary productivity in waterlimited ecosystems: how plants 'leverage' precipitation to 'finance' growth. New Phytol. 181, 5-8. doi: 10.1111/j.1469-8137.2008.02695.x

Foxx, A. J., and Florian, F. (2019). Root and shoot competition lead to contrasting competitive outcomes under water stress: a systematic review and metaanalysis. PLos One 14:e0220674. doi: 10.1101/712208

Fu, B. J., Li, S. G., Yu, X. B., Yang, P., Yu, G. R., Feng, R. G., et al. (2010). Chinese ecosystem research network: progress and perspectives. Ecol. Complex 7, 225-233. doi: 10.1016/j.ecocom.2010.02.007

Gao, Y., Duan, A. W., Sun, J. S., Li, F. S., Liu, Z. G., Liu, H., et al. (2009) Crop coefficient and water-use efficiency of winter wheat/spring maize strip intercropping. Field Crops Res. 111, 65-73. doi: 10.1016/j.fcr.2008.10.007

García-Cervigón, A. I., Gazol, A., Sanz, V., Camarero, J. J., and Olano, J. M. (2013). Intraspecific competition replaces interspecific facilitation as abiotic stress decreases: the shifting nature of plant-plant interactions. Perspect. Plant Ecol. 15, 226-236. doi: 10.1016/j.ppees.2013.04.001

Geijzendorffer, I. R., van der Werf, W., Bianchi, F. J. J. A., and Schulte, R. P. O. (2011). Sustained dynamic transience in a lotka-volterra competition model system for grassland species. Ecol. Modell. 222, 2817-2824. doi: 10.1016/j. ecolmodel.2011.05.029

Ghosh, P. K. (2004). Growth, yield, competition and economics of groundnut/cereal fodder intercropping systems in the semi-arid tropics of India. Field Crops Res. 88, 227-237. doi: 10.1016/j.fcr.2004.01.015

Grant, K., Kreyling, J., Heilmeier, H., Beierkuhnlein, C., and Jentsch, A. (2014). Extreme weather events and plant-plant interactions: shifts between

\section{FUNDING}

This study was financially supported by the National Natural Science Foundation of China (41701602 and 42067069), the Foundation of State Key Laboratory of Soil Erosion and Dryland Farming on the Loess Plateau (A314021402-2015), and the Key Research and Development Program of Shaanxi Province (2019SF-267).

competition and facilitation among grassland species in the face of drought and heavy rainfall. Ecol. Res. 29, 991-1001.

IPCC (2014). "Climate change 2014: synthesis report," in Proceeding of the Contribution of Working Groups I, II and III to the Fifth Assessment Report of the Intergovernmental Panelon Climate Change, eds R. K. Pachauri and R. L. J. Meyer 85-88. doi: 10.3167/147335304782369122

Jolliffe, P. A., Minjas, A. N., and Runecles, V. C. (1984). A reinterpretation of yield relationships in replacement series experiments. J. Appl. Ecol. 21, 227-243.

Knapp, A. K., Fay, P. A., Blair, J. M., Collins, S. L., Smith, M. D., Carlisle, J. D., et al. (2003). Rainfall variability, carbon cycling, and plant species diversity in a mesic grassland. Science 298, 2202-2205. doi: 10.1126/science.1076347

Lamb, E. G., Shore, B. H., and Cahill, J. F. (2007). Water and nitrogen addition differentially impact plant competition in a native rough fescue grassland. Plant Ecol. 192, 21-33. doi: 10.1007/s11258-006-9222-4

Lee, M. A., Manning, P., Walker, C. S., and Power, S. A. (2014). Plant and arthropod community sensitivity to rainfall manipulation but not nitrogen enrichment in a successional grassland ecosystem. Oecologia 176, 1173-1185. doi: 10.1007/ s00442-014-3077-5

Lithourgidis, A. S., Vlachostergios, D. N., Dordas, C. A., and Damalas, C. A. (2011). Dry matter yield, nitrogen content, and competition in pea-cereal intercropping systems. Eur. J. Agron. 34, 287-294. doi: 10.1007/s00442-0143077-5

Liu, Y. S., Pan, Q. M., Zheng, S. X., Bai, Y. F., and Han, X. G. (2012). Intra-seasonal precipitation amount and pattern differentially affect primary production of two dominant species of Inner Mongolia grassland. Acta. Oecol. 44, 2-10. doi: 10.1016/j.actao.2012.01.005

Manasa, P., Maitra, S., and Barman, S. (2020). Yield attributes, yield, competitive ability and economics of summer maize-legume intercropping system. Int. J. Agric. Environ. Biote. 13, 23-26. doi: 10.30954/0974-1712.1. 2020.16

Miao, C. Y., Sun, Q. H., Duan, Q. Y., and Wang, Y. F. (2016). Joint analysis of changes in temperature and precipitation on the Loess Plateau during the period 1961-2011. Clim. Dynam. 47, 3221-3234. doi: 10.1007/s00382-0163022-x

Niu, F. R., Duan, D. P., Chen, J., Xiong, P. F., Zhang, H., Wang, Z., et al. (2016). Ecopysiological responses of dominant species to watering in a natural grassland community on the semi-arid loess plateau of China. Front. Plant Sci. 7:663. doi: $10.3389 /$ fpls. 2016.00663

Niu, S. L., Xing, X. R., Zhang, Z., Xia, J. Y., Zhou, X. H., Song, B., et al. (2011). Water-use efficiency in response to climate change: from leaf to ecosystem in a temperate steppe. Global Chang Biol. 17, 1073-1082. doi: 10.1111/j.1365-2486. 2010.02280.x

Padilla, F. M., Miranda, J. D., Jorquera, J. M., and Pugnaire, F. I. (2009). Variability in amount and frequency of water supply affects roots but not growth of arid shrubs. Plant Ecol. 204, 261-270. doi: 10.1007/s11258-009-9589-0

Peng, S. S., Piao, S. L., Shen, Z. H., Ciais, P., Sun, Z. Z., Chen, S. P., et al. (2013). Precipitation amount, seasonality and frequency regulate carbon cycling of a semi-arid grassland ecosystem in Inner Mongolia, China: a modeling analysis. Agric. For Meteorol. 17, 46-55. doi: 10.1016/j.agrformet.2013. 02.002

Post, A. K., and Knapp, A. K. (2020). The importance of extreme rainfall events and their timing in a semi-arid grassland. J. Ecol. 108, 2431-2443. doi: 10.1111/ $1365-2745.13478$

Ren, Y. Y., Wang, X. L., Zhang, S. Q., Palta, J. A., and Cheng, Y. L. (2017). Influence of spatial arrangement in maize-soybean intercropping on root growth and water use efficiency. Plant Soil 415, 131-144. doi: 10.1007/s11104-016-3143-3 
Sammul, M., Kull, K., Oksanen, L., and Veromann, P. (2000). Competition intensity and its importance: results of field experiments with Anthoxanthum odoratum. Oecologia 125, 18-25. doi: 10.1007/pl00008887

Schwinning, S., Sala, O. E., Loik, M. E., and Ehleringer, J. R. (2004). Thresholds, memory, and seasonality: understanding pulse dynamics in arid/semi-arid ecosystems. Oecologia 141, 191-193. doi: 10.1007/s00442-004-1683-3

Shan, L., and Xu, B. C. (2009). Discuss about establishing stable artificial grassland in semiarid region on the Loess Plateau (in Chinese). Acta Pratacul. Sin. 18, 1-2. doi: 10.11686/cyxb20090201

Soliveres, S., Garcia-Palacios, P., Maestre, F. T., Escudero, A., and Valladares, F. (2013). Changes in rainfall amount and frequency do not affect the outcome of the interaction between the shrub Retama sphaerocarpa and its neighbouring grasses in two semiarid communities. J. Arid. Environ. 91, 104-112. doi: 10. 1016/j.jaridenv.2012.12.011

Soliveres, S., Monerris, J. J., and Cortina, J. (2012). Irrigation, organic fertilization and species successional stage modulate the response of woody juveniles to herbaceous competition in a semi-arid quarry restoration. Appl. Veg. Sci. 15, 175-186. doi: 10.1111/j.1654-109X.2011.01163.x

Wang, Z., Xu, W. Z., Chen, Z. F., Jia, Z., Huang, J., Wen, Z. M., et al. (2018). Soil moisture availability at early growth periods strongly affected root growth of Bothriochloa ischaemum when mixed with Lespedeza davurica. Front. Plant Sci. 9:1050. doi: 10.3389/fpls.2018.01050

Weigelt, A., and Jolliffe, P. (2003). Indices of plant competition. J. Ecol. 91, 707-720. doi: $10.2307 / 3599697$

Williams, A. C., and Mccarthy, B. C. (2001). A new index of interspecific competition for replacement and additive designs. Ecol Res. 16, 29-40. doi: 10.1046/j.1440-1703.2001.00368.x

Wilsey, B. J. (2010). Productivity and subordinate species response to dominant grass species and seed source during reoration. Reststor. Ecol. 18, 628-637. doi: 10.1111/j.1526-100x.2008.00471.x

Wilson, J. B. (1988). Shoot competition and root competition. J. Appl. Ecol. 25, 279-296. doi: 10.2307/2403626

Xiong, P. F., Shu, J. L., Zhang, H., Jia, Z., Song, J. X., Palta, J. A., et al. (2017). Small rainfall pulses affected leaf photosynthesis rather than biomass production of dominant species in semiarid grassland community on loess plateau of China. Funct. Plant Biol. 44, 1129-1242. doi: 10.1071/FP17040

Xu, B. C., Xu, W. Z., Gao, Z. J., Wang, J., and Huang, J. (2013). Biomass production, relative competitive ability and water use efficiency of two dominant species in semiarid loess plateau under different water supply and fertilization treatments. Ecol Res. 28, 781-792. doi: 10.1007/s11284-013-1061-x
Xu, B. C., Xu, W. Z., Huang, J., Shan, L., and Li, F. M. (2011a). Biomass allocation, relative competitive ability and water use efficiency of two dominant species in semiarid loess plateau under water stress. Plant Sci. 181, 644-651. doi: 10.1016/ j.plantsci.2011.03.005

Xu, B. C., Xu, W. Z., Huang, J., Shan, L., and Li, F. M. (2011b). Biomass production and relative competitiveness of a C3 legume and a C4 grass co-dominant in the semiarid Loess Plateau of China. Plant Soil 347, 25-39. doi: 10.1007/s11104011-0724-Z

Xu, W. Z., Deng, X. P., Wang, Z., Xu, B. C., and Wang, X. L. (2017). Leaf photosynthetic characteristics of Bothriochloa ischaemum and Lespedeza davurica in mixtures under water stress. Acta Bot. Boreali Occidentalia Sin. 37, 1155-1165. doi: 10.7606/j.issn.1000-4025.2017.06.1155

Xu, W. Z., Deng, X. P., Xu, B. C., Gao, Z. J., and Ding, W. L. (2014). Photosynthetic activity and efficiency of Bothriochloa ischaemum and Lespedeza davurica in mixtures across growth periods under water stress. Acta Physiol. Plant 36, 1033-1044. doi: 10.1007/s11738-013-1481-9

Yu, Y., Stomph, T. J., Makowski, D., Zhang, L. Z., and van der Werf, W. (2016). A meta-analysis of relative crop yields in cereal/legume mixtures suggests options for management. Field Crops Res. 198, 269-279. doi: 10.1016/j.fcr.2016. 08.001

Zhang, B., Zhu, J. J., Pan, Q. M., Liu, Y. S., Chen, S. P., Chen, D. M., et al. (2017). Grassland species respond differently to altered precipitation amount and pattern. Environ. Exp. Bot. 137, 166-176. doi: 10.1016/j.envexpbot.2017.02.006

Conflict of Interest: The authors declare that the research was conducted in the absence of any commercial or financial relationships that could be construed as a potential conflict of interest.

Publisher's Note: All claims expressed in this article are solely those of the authors and do not necessarily represent those of their affiliated organizations, or those of the publisher, the editors and the reviewers. Any product that may be evaluated in this article, or claim that may be made by its manufacturer, is not guaranteed or endorsed by the publisher.

Copyright (c) $2021 \mathrm{Xu}$, Deng, Xu, Palta and Chen. This is an open-access article distributed under the terms of the Creative Commons Attribution License (CC BY). The use, distribution or reproduction in other forums is permitted, provided the original author(s) and the copyright owner(s) are credited and that the original publication in this journal is cited, in accordance with accepted academic practice. No use, distribution or reproduction is permitted which does not comply with these terms. 